\title{
OPEN
}

\section{Author Correction: Efficient Alpha Radiation Detector using Low Temperature Hydrothermally Grown ZnO:Ga Nanorod Scintillator}

\section{R. M. Sahani, Chandni Kumari, Arun Pandya \& Ambesh Dixit (D) \\ Correction to: Scientific Reports https://doi.org/10.1038/s41598-019-47732-1, published online 06 August 2019 \\ This Article contains an error in Figure 7, in which Panel A was a duplication of Panel B. The correct Figure 7 appears below as Figure 1.}

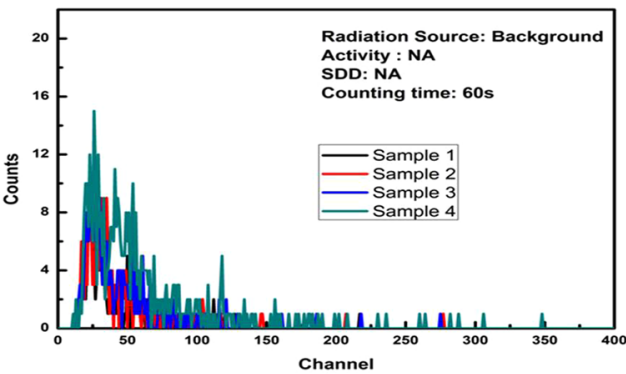

(a)

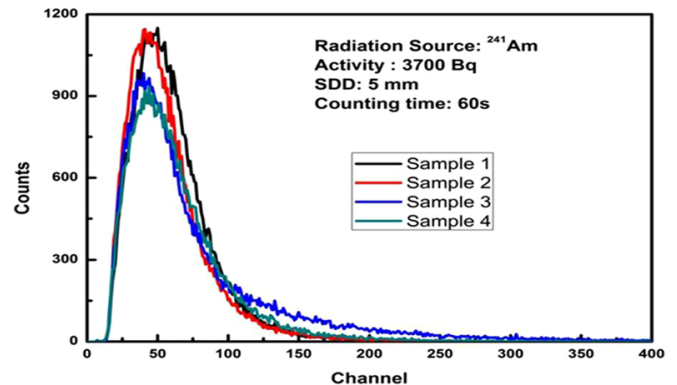

(c)

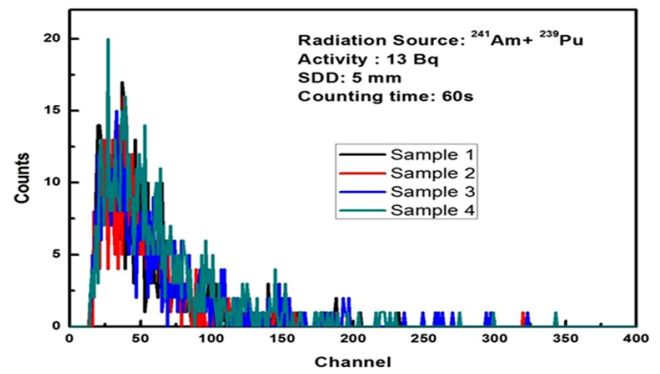

(b)

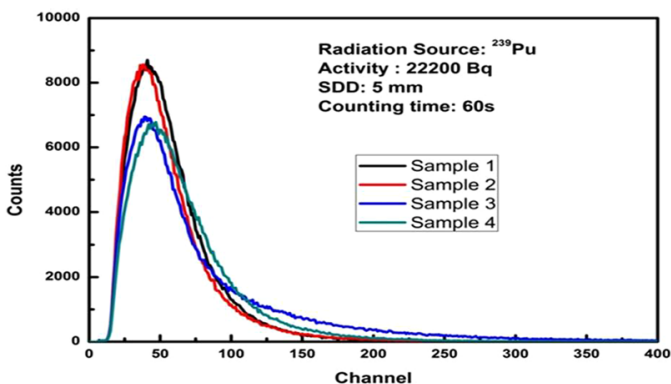

(d)

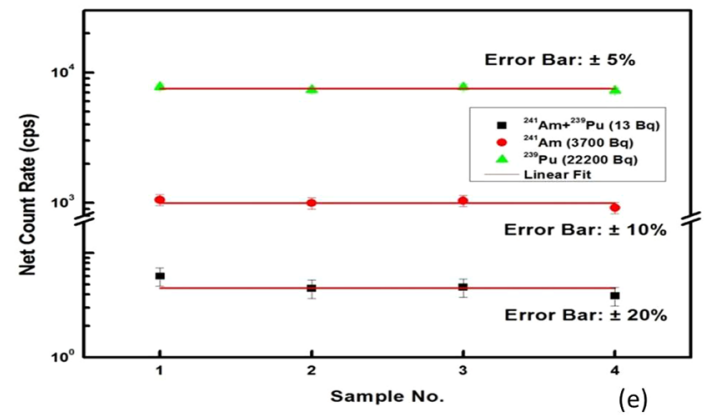

Figure 1. 
Additionally, this Article contains typographical errors in the Introduction:

"Alpha radiation, one form of Ionizing radiation, is a stream of doubly charged particles and is emitted from radioactive decay of a heavy nucleus, D-T or D-D reactions ${ }^{1}$."

should read:

"Alpha radiation, one form of Ionizing radiation, is a stream of doubly charged particles and is emitted from radioactive decay of a heavy nucleus and D-T reaction ${ }^{1}$."

"In a neutron generator utilizing D-D to D-T reaction for emission of monoenergetic neutrons for nuclear material interrogation purpose, monitoring of alpha radiation generated in opposite to neutrons is used for associated particle imaging"."

should read:

In a neutron generator utilizing D-T reaction for emission of monoenergetic neutrons for nuclear material interrogation purpose, monitoring of alpha radiation generated in opposite to neutrons is used for associated particle imaging."

(1) Open Access This article is licensed under a Creative Commons Attribution 4.0 International License, which permits use, sharing, adaptation, distribution and reproduction in any medium or format, as long as you give appropriate credit to the original author(s) and the source, provide a link to the Creative Commons license, and indicate if changes were made. The images or other third party material in this article are included in the article's Creative Commons license, unless indicated otherwise in a credit line to the material. If material is not included in the article's Creative Commons license and your intended use is not permitted by statutory regulation or exceeds the permitted use, you will need to obtain permission directly from the copyright holder. To view a copy of this license, visit http://creativecommons.org/licenses/by/4.0/.

(c) The Author(s) 2020 